\title{
BRCA1 Protein Expression Predicts Survival in Glioblastoma Patients from an NRG Oncology RTOG Cohort
}

\author{
Maria Vassilakopoulou ${ }^{a, b}$ Minhee Won ${ }^{c}$ Walter J. Curran ${ }^{d}$ Luis Souhami $^{\mathrm{e}}$ \\ Michael D. Prados ${ }^{f}$ Corey J. Langer ${ }^{g}$ David L. Rimm ${ }^{a}$ Jason A. Hanna ${ }^{a}$ h \\ Veronique M. Neumeister ${ }^{a}$ i $\quad$ Edward Melian ${ }^{j} \quad$ Aidnag Z. Diaz ${ }^{k}$ \\ James N. Atkins' Lydia T. Komarnicky ${ }^{m}$ Christopher J. Schultz ${ }^{\text {n }}$ \\ Steven P. Howard ${ }^{\circ}$ Peixin Zhang ${ }^{c}$ Adam P. Dicker ${ }^{p}$ Jonathan P.S. Knisely ${ }^{q}$ \\ aDepartment of Pathology, Yale University, New Haven, CT, USA; ${ }^{\circ}$ Department of Medical Oncology, University \\ of Crete, Heraklion, Greece; 'NRG Oncology Statistics and Data Management Center, Philadelphia, PA, USA; \\ ${ }^{\mathrm{d} D e p a r t m e n t}$ of Radiation Oncology, Winship Cancer Institute, Emory University, Atlanta, GA, USA; 'Department \\ of Radiation Oncology, McGill University, Montréal, QC, Canada; fDepartment of Neurological Surgery, \\ University of California, San Francisco, CA, USA; 9Division of Hematology Oncology, University of Pennsylvania, \\ Philadelphia, PA, USA; ' ${ }^{n}$ Department of Biological Sciences and Center for Cancer Research, Purdue University, \\ West Lafayette, IN, USA; 'Akoya Biosciences, Hopkinton, MA, USA; jDepartment of Radiation Oncology, Loyola \\ University Medical Center, Maywood, IL, USA; ${ }^{k}$ Department of Radiation Oncology, Rush University Medical \\ Center, Chicago, IL, USA; 'Southeast Cancer Consortium-Upstate NCORP, Winston-Salem, NC, USA; mDepartment \\ of Radiation Oncology, Drexel University School of Medicine, Philadelphia, PA, USA; ${ }^{n}$ Department of Radiation \\ Oncology, Medical College of Wisconsin, Milwaukee, WI, USA; ${ }^{\circ}$ Department of Human Oncology, University of \\ Wisconsin Hospital, Madison, WI, USA; PDepartment of Radiation Oncology, Thomas Jefferson University, \\ Philadelphia, PA, USA; 'Department of Radiation Oncology, Weill Cornell Medicine, New York, NY, USA
}

\section{Keywords}

BRCA1 - Glioblastoma · Biomarker · Tissue microarrays

\begin{abstract}
Purpose: Glioblastoma, the most common malignant brain tumor, was associated with a median survival of $<1$ year in the pre-temozolomide (TMZ) era. Despite advances in molecular and genetic profiling studies identifying several predictive biomarkers, none has been translated into routine clinical use. Our aim was to investigate the prognostic significance of a panel of diverse cellular molecular markers of tumor formation and growth in an annotated glioblastoma tissue microarray (TMA). Methods and Materials: A TMA composed of archived glioblastoma tumors from patients
\end{abstract}

karger@karger.com www.karger.com/ocl

Karger $\frac{1}{\%}$
(C) 2021 The Author(s)

Published by S. Karger AG, Basel

This is an Open Access article licensed under the Creative Commons Attribution-NonCommercial-4.0 International License (CC BY-NC) (http://www.karger.com/Services/OpenAccessLicense), applicable to the online version of the article only. Usage and distribution for commercial purposes requires written permission. treated with surgery, radiation, and non-TMZ chemotherapy, was provided by RTOG. RAD51, BRCA-1, phosphatase and tensin homolog tumor suppressor gene (PTEN), and miRNA-210 expression levels were assessed using quantitative in situ hybridization and automated quantitative protein analysis. The objectives of this analysis were to determine the association of each biomarker with overall survival (OS), using the Cox proportional hazard model. Event-time distributions were estimated using the Kaplan-Meier method and compared by the log-rank test. Results: A cohort of 66 patients was included in this study. Among the 4 biomarkers assessed, only BRCA1 expression had a statistically significant correlation with survival. From univariate analysis, patients with low BRCA1 protein expression showed a favor- 
able outcome for OS ( $p=0.04$; hazard ratio $=0.56$ ) in comparison with high expressors, with a median survival time of 18.9 versus 4.8 months. Conclusions: BRCA1 protein expression was an important survival predictor in our cohort of glioblastoma patients. This result may imply that low BRCA1 in the tumor and the consequent low level of DNA repair cause vulnerability of the cancer cells to treatment.

(c) 2021 The Author(s)

Published by S. Karger AG, Basel

\section{Introduction}

Glioblastoma is the most frequent and the most malignant primary brain tumor [1]. The treatment for newly diagnosed glioblastoma involves maximal safe surgery plus radiation therapy in combination with alkylating agents [2, 3]. Survival has improved since 2005, when a randomized controlled study demonstrated that the addition of temozolomide (TMZ) to radiation therapy after surgery improved survival compared to postoperative radiotherapy alone [4]. Nevertheless, despite treatment, most patients relapse, and the median survival for all glioblastoma patients remains below 15 months $[4,5]$.

Genetic and environmental risk factors have been studied in glioblastoma, but none has been identified as causative; most tumors are considered sporadic [6]. Several prognostic factors have been reported to affect survival, including tumor size and location, age and Karnofsky performance score at presentation, and extent of surgical resection [7]. Various prognostic molecular biomarkers have been identified in glioblastoma, including the methylation status of the promoter sequence of the O6-methylguanine-DNA methyltransferase(MGMT) gene, mutations of the enzymes isocitrate dehydrogenase $1 / 2$ (IDH1/2), epidermal growth factor receptor overexpression, mutations of the tumor protein 53 (TP53), and mutations of the phosphatase and tensin homolog tumor suppressor gene (PTEN) [7]. Nevertheless, none has been translated into routine clinical use.

The lack of efficacy of current therapeutic modalities and the fact that most glioblastoma tumors recur within the previously irradiated field indicate the existence of resistant cell populations, and therefore, identifying possible mechanisms of resistance is extremely important to improve on current therapeutic approaches. Among potential mechanisms of resistance, DNA repair is believed to play a major role $[8,9]$.

There are several molecules with possible implication in glioblastoma therapeutic resistance, including RAD51, an enzyme involved in homologous recombination DNA repair, which may contribute to resistance to cross-linking of double-stranded DNA by alkylating agents since stabilization of RAD51-containing intermediates is required for efficient mismatch repair of interstrand crosslinks $[10,11]$. Moreover, it has been reported that elevated levels of RAD51 predict both recurrence-free and overall survival (OS) in glioblastoma patients [12].

MicroRNAs (miRs) are small, noncoding RNA molecules that have been shown to play a role in oncogenesis by altering mRNA transcripts and therefore posttranscriptionally regulating gene expression [13]. miR-210 is hypoxia-induced and highly dysregulated in glioblastomas [14-16].

The tumor suppressor proteins PTEN and BRCA1 both play an important role in DNA damage repair; they functionally cooperate and constitute a substantial blockage to the development of cancer. They are frequently mutated or deleted in many human tumors. Loss or decrease of PTEN or BRCA1 function, through mutation or reduced expression, might contribute to oncogenesis [16]. Interestingly, activation of the phosphatidylinositol3-OH kinase $(\mathrm{PI} 3 \mathrm{~K}) /$ protein kinase B (AKT) pathway and co-expression of activated AKT with intact BRCA1 decreases radiation sensitivity. Moreover, inactivation of PTEN can trigger the PI3K/AKT pathway, which occurs frequently in glioblastomas and correlates with radioresistance [17].

BRCA1 is a tumor suppressor gene and the first gene that was identified in early-onset familial breast and ovarian cancers [18]. It encodes for a multifunctional protein involved in DNA repair, chromatin remodeling, and cell cycle regulation, and its mutations lead to failures in DNA damage repair, genetic alterations, and cancer [19]. BRCA1 is a phosphorylation substrate of the kinase ataxia telangiectasia mutated (ATM) and is required for a normal response to ionizing radiation and to alkylating agents [20]. Sporadic cases of glioblastoma have been reported in patients carrying BRCA1 germ line mutations, but the BRCA1 expression status has never been systematically studied in glioblastoma patients $[21,22]$.

In this study, we sought to determine the expression level and prognostic significance of a panel of diverse biomarkers related to tumor formation and growth, hypoxia, and resistance to treatment in an annotated glioblastoma cohort that had been treated in the pre-TMZ era with surgery followed by protocol-based chemo-radiotherapy on the National Cancer Institute (NCI)-sponsored clinical trials conducted under the aegis of the Radiation Therapy Oncology Group. 


\section{Materials and Methods}

Patient Cohort and Tissue Microarray Construction

This study was conducted retrospectively in a cohort of patients with glioblastoma from 8 different RTOG trials treated with surgical resection followed by external beam irradiation, with or without non-TMZ chemotherapy. A tissue microarray (TMA) was constructed, composed of histospots from the archived formalinfixed paraffin embedded (FFPE) tumors of the above cohort. All institutions obtained institutional review board approval prior to patient recruitment, and all patients signed approved informed consent documents prior to trial enrollment.

\section{MicroRNA in situ Hybridization}

MicroRNA in situ hybridization was performed, as previously described [23]. In brief, FFPE TMAs were melted at $60^{\circ} \mathrm{C}$ for 10 min, deparaffinized in xylene, rehydrated in ethanol gradient, then treated with $20 \mu \mathrm{g} / \mathrm{mL}$ proteinase $\mathrm{K}$ (Roche Diagnostics, Indianapolis, IN, USA) for $10 \mathrm{~min}$ in $37^{\circ} \mathrm{C}$, fixed with $4 \%$ formaldeyde (Thermo Scientific, Rockford, IL, USA), rinsed twice in $0.13 \mathrm{M}$ 1-methylimidazole, and refixed with 1-ethyl-3-(3-dimethylaminopropyl) carbodiimide (Thermo Scientific) for $1 \mathrm{~h}$. Next, endogenous peroxidases are blocked with $1 \% \mathrm{H}_{2} \mathrm{O}_{2}$ for 30 min, and slides are prehybridized at a hybridization temperature of $50^{\circ} \mathrm{C}$ for 30 min in hybridization buffer containing $50 \%$ formamide (American Bioanalytical, Natick, MA, USA), $5 \times$ saline-sodium citrate ([SSC], American Bioanalytical), $50 \mu \mathrm{g} / \mathrm{mL}$ heparin (Sigma-Aldrich, St. Louis, MO, USA), 0.1\% Tween 20 (Sigma), and $500 \mu \mathrm{g} /$ mL yeast tRNA (Invitrogen, Carlsbad, CA, USA) adjusted to pH 6 . Slides were hybridized for $1 \mathrm{~h}$ with $200 \mathrm{nM}$ double digoxigenin (DIG) locked nucleic acid-modified probes (Exiqon, Copenhagen, Denmark) for miR-210 (sequence: $5^{\prime}$-AGCCCCUGCCCACCGCACACUG- $3^{\prime}$ ) and scrambled probe (sequence: $5^{\prime}$-GTGTAACACGTCT-ATACGCCCA- $3^{\prime}$ ) and $25 \mathrm{nM} 5^{\prime}$ DIG-labeled probe for the U6 Probe (sequence: $5^{\prime}$-CACGAATTTGCGTGTCATCCTT $-3^{\prime}$ ). The slides were then stringently washed in $2 \times$ SSC (once at hybridization temperature and then twice at room temperature for $5 \mathrm{~min}$ each), blocked with $2 \%$ bovine serum albumin (Sigma-Aldrich) for $30 \mathrm{~min}$, and incubated with anti-DIG-POD, Fab fragments from sheep (Roche Diagnostics) diluted 1:100 and rabbit anti-cytokeratin (Dako Corp., Carpinteria, CA, USA) diluted 1:100 in block ( $2 \%$ bovine serum albumin in PBS) at room temperature for $1 \mathrm{~h}$. The slides were then washed twice with $0.1 \%$ Tween PBS and once washed in PBS for $5 \mathrm{~min}$ each. Then, the miRNA signal was detected with the TSA Plus Cyanine 5 system (Perkin Elmer, Norwalk, CT, USA); the slides were washed again with Tween PBS and PBS as above, and cytokeratin was detected with Alexa 546-conjugated goat anti-rabbit secondary antibody (Molecular Probes) diluted 1:100 in block solution for $1 \mathrm{~h}$, and the slides were mounted with ProLong mounting medium containing 4',6-diamidino-2-phenylindole (DAPI, Molecular Probes, Eugene, OR, USA).

\section{Quantitative Immunofluorescence}

In situ quantitative measurement of biomarkers was done by using the following:

- anti-BRCA1 mouse monoclonal antibody (Calbiochem);

- anti-RAD51 mouse monoclonal antibody (Thermo Scientific);

- anti-PTEN rabbit monoclonal antibody (Cell Signaling Technologies).
Table 1. Patient pretreatment characteristics

\begin{tabular}{lc}
\hline Age, years & \\
Median & 57 \\
Minimum-maximum & $25-79$ \\
Q1-Q3 & $51-64$ \\
Prior surgery, $n$ (\%) & \\
Biopsy & $7(10.6)$ \\
Partial resection & $35(53.0)$ \\
Total resection & $23(34.8)$ \\
Other & $1(1.5)$ \\
Neurologic function deficit, $n(\%)$ & \\
None/minor & $34(51.5)$ \\
Moderate & $24(36.4)$ \\
Severe & $8(12.1)$ \\
Histology, $n(\%)$ & \\
GBM & $64(97.0)$ \\
AA* & $2(3.0)$ \\
RPA class, $n(\%)$ & \\
I & $1(1.5)$ \\
III & $7(10.6)$ \\
IV & $29(43.9)$ \\
V & $19(28.8)$ \\
VI & $10(15.2)$ \\
\end{tabular}

GBM, glioblastoma multiforme; RPA, recursive partitioning analysis; AA, anaplastic astrocytoma. ${ }^{*}$ These are from RTOG 9404.

TMA sections were deparaffinized and stained, and each antibody was validated by titrating and reproducibility assessments on index arrays according to a standard previously described protocol [24].

In brief, TMA slides were deparaffinized with xylene and then rehydrated with ethanol. Antigen retrieval was performed using a PT module (Lab Vision Corp., Fremont, CA, USA) with EDTA buffer, $\mathrm{pH} 8$, at $97^{\circ} \mathrm{C}$ for $20 \mathrm{~min}$ for BRCA1 and with citrate buffer, $\mathrm{pH}=6$, at $97^{\circ} \mathrm{C}$ for 20 min for PTEN and Rad51 antibodies, respectively. Endogenous peroxidase activity was blocked via $30-$ min incubation in $2.5 \%$ hydrogen peroxide in methanol at room temperature, and thereafter, slides were incubated with the primary antibody and glial fibrillary acidic protein (GFAP; Rabbit polyclonal, Neuromics, Edina, MN, USA) overnight at $4^{\circ} \mathrm{C}$. Staining was performed by using the Thermo/Fisher Lab Vision autostainer. We used as secondary antibody Alexa 546 conjugated goat antirabbit/mouse (Molecular Probes) with mouse/ rabbit EnVision reagent (DAKO) followed by Cy5-tyramide (Perker Elmer, Life Science, MA, USA). DAPI was used to stain the cell nuclei.

\section{Quantitative Immunofluorescence}

The automated quantitative analysis (AQUA) of quantitatively measuring immunofluorescence allows accurate and objective measurement of fluorescence intensity within a defined tumor area, as well as within subcellular compartments, as described previously [25]. In brief, for this work, a series of high-resolution monochromatic images were captured using an Olympus AX-51 epifluorescent microscope based on a previously described algo- 
Fig. 1. AQUA images of BRCA1 protein expression. An example of a GBM specimen with high BRCA1 protein expression with representative fluorescent AQUA microphotograph. GBM, glioblastoma multiforme; AQUA, automated quantitative protein analysis.
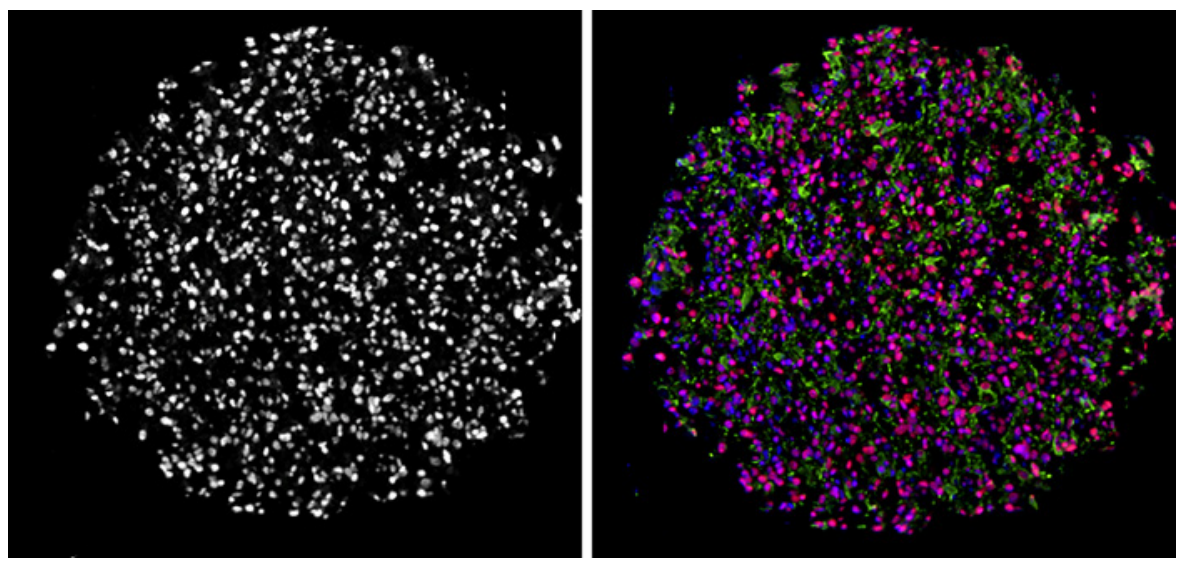

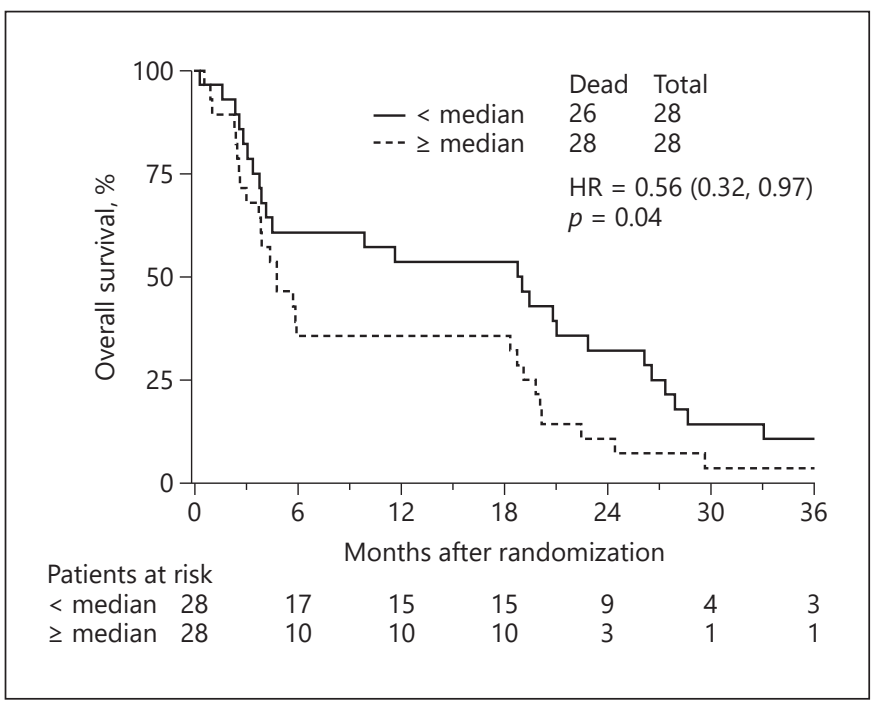

Fig. 2. Kaplan-Meier survival curve for BRCA1 protein. HR, hazard ratio; OS, overall survival.

rithm. According to this algorithm, images were obtained for each histospot and for each different fluorescence channel, DAPI (nuclei), GFAP (glial cells), or Cy5 (target probe), respectively. A tumor mask was created by binarizing the cytokeratin signal to distinguish the stromal area from the tumor area; target probe expression is quantified only within the tumor. AQUA scores were calculated for a given target within the "tumor mask" by dividing the signal intensity in pixels by the area of the "tumor mask" within each histospot. Histospots containing $<5 \%$ tumor, as determined by the percentage of area which was positive for GFAP, were excluded from the analysis.

\section{Statistical Analysis}

The objectives of this analysis were to determine the association of each biomarker with OS. All biomarkers were scored as continuous variables. BRCA1, PTEN, RAD51 and, miRNA210 scores were dichotomized with respect to their corresponding median AQUA scores. For the analyses on each biomarker, patients' pre- treatment characteristics were compared between the groups of patients with lower and higher expressions. Event-time distributions on OS were estimated using the Kaplan-Meier method [26] and compared using the log-rank test [27].

Multivariate Cox regression models [28] were used to assess the effect of each marker after adjusting for patients' pretreatment characteristics and recursive partitioning analysis class. Statistical analysis was performed using SAS version 9.2.

\section{Results}

\section{Baseline Clinical and Experimental Data}

Glioblastoma tumors from a cohort of 66 patients with survival information were evaluated for miR210, Rad51, PTEN, and BRCA1 protein levels. The clinicopathologic characteristics of the patient cohort are shown in Table 1. The median age was 57 (range 25-79) years, and a majority of the patients underwent either partial or total resection. Depending on the tumor area and histospots quality, BRCA1 protein levels were measured in 56 FFPE specimens (Fig. 1).

\section{BRCA1 Showed a Significant Correlation with \\ Survival}

Among the 4 biomarkers assessed, only BRCA1 expression had a statistically significant correlation with survival. For the 56 patients evaluable for BRCA1 expression and with survival information, the low- and highBRCA1 level groups were well-balanced in terms of clinical variables (Table 2). Patients with lower BRCA1 protein expression showed a favorable outcome for OS, with a median survival time of 18.9 months, compared to 4.8 months for patients with higher expression (Table 3; Fig. 2). This is corresponding to a hazard ratio (HR) of 0.56 (95\% confidence interval: $0.32-0.97)$, with $p$ value $=$ 
Table 2. Patient pretreatment characteristics by BRCA1 levels

\begin{tabular}{|c|c|c|c|}
\hline & $<$ Median $(n=28), n(\%)$ & $\geq$ Median $(n=28), n(\%)$ & $\chi^{2} p$ value \\
\hline \multicolumn{4}{|l|}{ Age } \\
\hline $18-30$ years & $1(3.6)$ & $1(3.6)$ & \multirow{3}{*}{0.60} \\
\hline $31-49$ years & $7(25.0)$ & $4(14.3)$ & \\
\hline$\geq 50$ years & $20(71.4)$ & $23(82.1)$ & \\
\hline Prior surgery & \multicolumn{2}{|c|}{ Biopsy versus partial versus total resection } & \multirow{5}{*}{0.38} \\
\hline Biopsy & $1(3.6)$ & $3(10.7)$ & \\
\hline Partial resection & $18(64.3)$ & $14(50.0)$ & \\
\hline Total resection & $8(28.6)$ & $11(39.3)$ & \\
\hline Other & $1(3.6)$ & $0(0.0)$ & \\
\hline \multicolumn{4}{|c|}{ Neurologic function deficit } \\
\hline None/minor & $15(53.6)$ & $15(53.6)$ & \multirow{3}{*}{0.88} \\
\hline Moderate & $10(35.7)$ & $11(39.3)$ & \\
\hline Severe & $3(10.7)$ & $2(7.1)$ & \\
\hline \multicolumn{4}{|l|}{ Histology } \\
\hline GBM & $26(92.9)$ & $28(100.0)$ & \multirow{2}{*}{0.15} \\
\hline $\mathrm{AA}^{*}$ & $2(7.1)$ & $0(0.0)$ & \\
\hline \multicolumn{4}{|l|}{ RPA class } \\
\hline I & $1(3.6)$ & $0(0.0)$ & \multirow{5}{*}{0.61} \\
\hline III & $3(10.7)$ & $3(10.7)$ & \\
\hline IV & $15(53.6)$ & $11(39.3)$ & \\
\hline $\mathrm{V}$ & $6(21.4)$ & $9(32.1)$ & \\
\hline VI & $3(10.7)$ & $5(17.9)$ & \\
\hline
\end{tabular}

GBM, glioblastoma multiforme; AA, anaplastic astrocytoma; RPA, recursive partitioning analysis. ${ }^{*}$ These are from RTOG 9404.

Table 3. OS by BRCA1 protein level

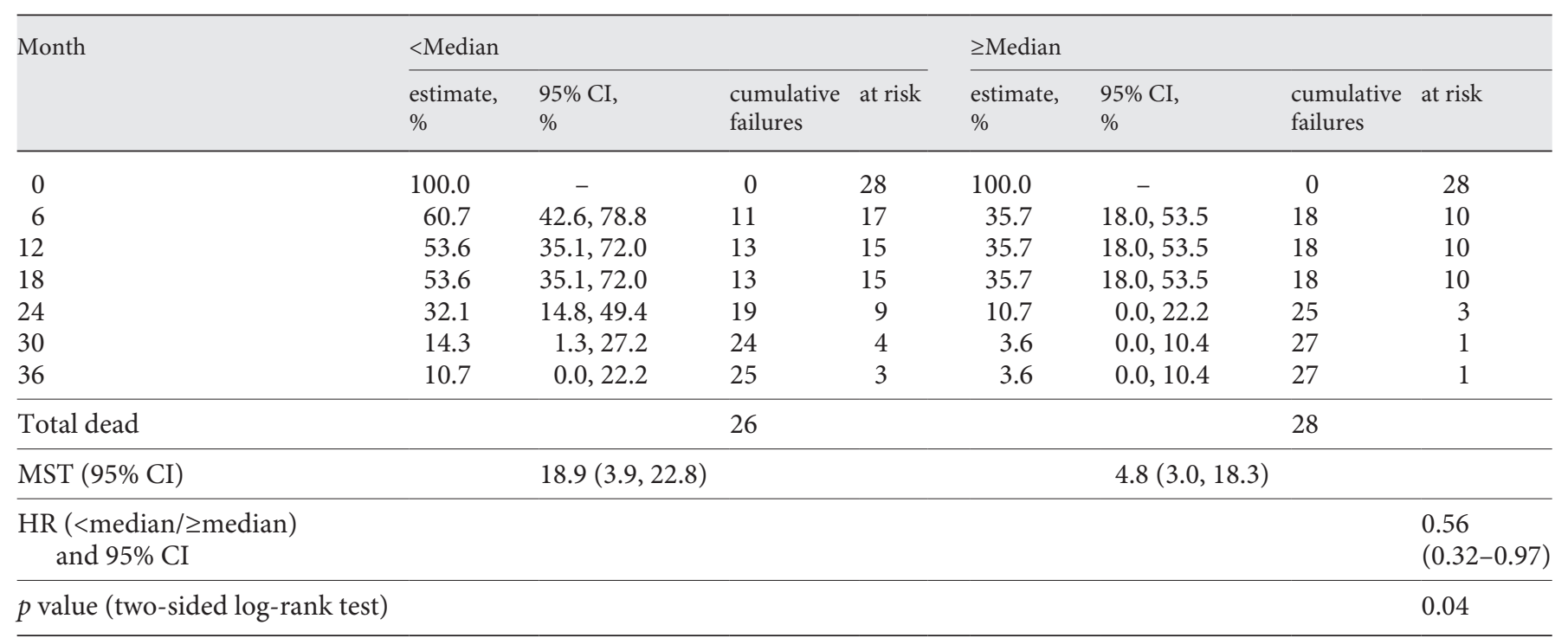

MST, median survival time; HR, hazard ratio; CI, confidence interval; OS, overall survival. 
Table 4. Multivariate (Cox proportional hazards) analysis for OS by BRCA1 protein level, adjusted by RPA classification

\begin{tabular}{lrl}
\hline Variable & $p$ value & HR $(95 \%$ CI $)$ \\
\hline BRCA1 (<median vs. $\geq$ median $)$ & 0.016 & $0.49(0.27,0.88)$ \\
RPA (I, III vs. V, VI) & $<0.001$ & $0.17(0.06,0.45)$ \\
RPA (IV vs. V, VI) & 0.059 & $0.56(0.31,1.02)$ \\
\hline
\end{tabular}

Bolded value has unfavorable outcome. HR, hazard ratio; OS, overall survival; RPA, recursive partitioning analysis; CI, confidence interval.

0.04. In the multivariate analysis, BRCA1 maintained its prognostic significance after adjusting for the known prognostic factor, recursive partitioning analysis, with an HR of 0.49 (95\% confidence interval: $0.27-0.88$ ) and $p$ value $=0.016$ (Table 4$)$.

\section{Discussion}

Our study showed for the first time that BRCA1 protein expression is related to glioblastoma survival in a cohort of patients assembled in the pre-TMZ era. The distinction between high and low expressors was quantitatively assessed using AQUA, which is acknowledged as providing more accurate results than routine immunohistochemistry (IHC).

BRCA1 gene is a tumor suppressor gene involved in DNA repair, and its mutations or deficient BRCA1 protein due to epigenetic alterations leads to DNA damage repair failure. BRCA1 protein is believed to play a central role in the DNA damage response mechanism of the mammalian cells by repairing double-strand breaks (DSBs) via errorfree homologous recombination, and it has been shown that several downstream proteins required for checkpoint activation and apoptosis require BRCA1 for their DNA damage-induced phosphorylation [29].

Although the role of BRCA1 gene and its germ line mutations is well established in the development of breast and ovarian cancers $[18,19]$, there is no known association between BRCA1 gene and gliomagenesis [30-32]. A study in a small cohort of glioblastoma patients using next-generation sequencing showed BRCA1 gene alterations that might support their role in glioblastoma predisposition [33].

Two cases of glioblastoma in BRCA1 germ line mutation carriers have been reported, but it was shown that BRCA1 expression is maintained both at protein and mRNA levels, suggesting that BRCA1 germ line mutation

BRCA1 Protein Predicts Survival in Glioblastoma Multiforme is not substantially important for glioblastoma multiforme development [21]. BRCA1 protein has been extensively studied in ovarian cancer, and it has been shown that ovarian cancer related to BRCA1 mutations are more responsive to platinum-based treatment and have better survival rates compared to non-BRCA1-mutated sporadic cancers [34]. Although in $80 \%$ of BRCA1-mutated breast and ovarian cancers, protein expression is lost because of deletion of the second allele $[35,36]$, it has been reported that in the majority of sporadic epithelial ovarian cancers, there is a BRCA1 protein dysfunction or reduced expression due to somatic mutations or epigenetic alterations [37-39]. Moreover, preclinical studies using in vitro and in vivo models have shown that low BRCA1 mRNA and protein expression is related to sensitivity and apoptotic response to platinum agents, this phenomenon being also present in normal cells [40, 41]. Additionally, studies of patients with analysis of BRCA1 protein expression by IHC or at the mRNA level showed that a decreased BRCA1 level was protective and predictive of a better OS in patients with sporadic epithelial ovarian cancer who received platinumbased treatment $[42,43]$.

As a result, although BRCA1 deficiency is clearly a disadvantage in terms of innate cellular tumorigenic potential, this state can be advantageous in the context of treatment effectiveness as this DNA repair deficiency leads to a vulnerability of these cells to DNA-damaging agents [44].

In our study, we showed a correlation between BRCA1 protein expression and OS in a cohort of glioblastoma patients treated with radiotherapy with or without various systemic therapies in the pre-TMZ era. A combination of radiotherapy with alkylating agents has long been the mainstay in the postoperative treatment of glioblastomas, but these tumors are well known for radioresistance and nearly universal relapse rates. Nevertheless, in our study, the patients with lower BRCA1 protein expression showed a favorable survival tendency.

Ionizing irradiation produces a variety of DNA lesions, including single-strand DNA breaks (SSBs) and DSBs. DSBs are considered to be the most important factor responsible for cell death. The repair of DSBs is dependent on ATM kinase activity, and this pathway has been shown to require a functional BRCA1 protein. DSBs induced by ionizing irradiation initiate a complex cellular response through ATM kinase activation, including checkpoint signaling and a cascade of phosphorylation events of several key proteins including BRCA1, followed by either DNA repair or apoptosis $[45,46]$.

BRCA1 is a target for phosphorylation for several checkpoint kinases, and these modifications are essential for a 
proper response to DNA damage induced by irradiation [47]. Intact BRCA1 is required for regular response to DNA damage induced by radiation and alkylating agents, and therefore, BRCA1 defective cells are more sensitive to these treatments as they have a compromised ability to respond to cytotoxic agents $[48,49]$.

BRCA1 protein expression, as measured by the AQUA of quantitative immunofluorescence, was an important prognostic determinant in our cohort of glioblastoma patients treated with surgery followed by radiotherapy or chemoradiotherapy. An increased sensitivity of glioblastoma cells to these treatments due to a defective BRCA1 protein is possibly the case in our study, which strongly suggests lower BRCA1 protein expression and a consequently low ability to effectively carry out DNA repair causes an enhanced vulnerability of the cancer cells to DNA-damaging therapies in cancer patients.

Moreover, as the presence of functional BRCA1 protein seems to be a predictive biomarker of an unfavorable survival outcome, it may be the case that agents that downregulate BRCA1 expression could be exploited as a novel therapeutic strategy for glioblastoma patients with normal or high BRCA1 protein levels, by sensitizing them to DNAdamaging treatment. Simply restated, targeting BRCA1 may modulate DNA repair and potentially improve the efficacy of radiotherapy and alkylating agents in glioblastoma patients.

Poly ADP-ribose inhibitors (PARPi) inhibit the enzymatic repair of SSBs. If SSBs are unrepaired at the time that DNA is replicated, the DNA replication process may turn these SSBs into DSBs. In BRCA-deficient cells, these DSBs cannot be efficiently repaired, leading to cellular apoptosis. In cells with normal BRCA levels, these DSBs can be repaired. In fact, PARPi have become important treatment options for women with BRCA-mutated ovarian [50] and breast cancers [51]. Moreover, the US Food and Drug Administration has recently approved PARPi for BRCA-mutated or ATM gene-mutated castration-resistant prostate cancer [52] and for BRCA-mutated pancreatic cancer [53].

Indeed, in vitro and in vivo preclinical data have been published, supporting the use of PARPi in combination with other cytotoxic treatments like TMZ and radiotherapy in glioblastoma cell lines or xenograft models. The data presented in these studies suggest that PARPi potentiates glioblastoma cell death and is capable of enhancing the cytotoxicity of the current standard treatment, and support the development of clinical trials [54-56]. Furthermore, irrespective of the BRCA1 status, a number of phase I/II clinical trials have been conducted and are currently underway investigating the use of PARPi in combination with other treatments in glioblastoma [57]. Therefore, it is of great importance to identify predictive biomarkers that will help select the subset of patients who will derive benefit from these agents, allowing patient stratification in clinical trials and further drug development.

BRCA1, BRCA2, and other molecules critical to the repair of DSBs may provide clinically useful predictive biomarkers for molecularly targeting a specific subpopulation of glioblastoma patients. However, distinguishing which patients may benefit and the selection of the cutoff point can be particularly difficult, especially at the protein level via IHC, a more subjective and qualitative scoring method. This problem may be resolved by using quantitative methods such as AQUA that can provide more accurate and objective results and can facilitate the distinction between high and low expressors in a population of low baseline levels.

In consequence, our results strongly suggest that BRCA1 protein expression is a potential predictive biomarker in glioblastoma, and our results may also provide interesting leads for novel therapeutic strategies. Since low BRCA1 protein expression is favorable for survival by rendering the tumor cells more sensitive to treatment, targeting BRCA1 might be a promising approach for these lethal tumors. Undoubtedly, further molecular and clinical studies are needed to consolidate these findings and to offer more robust elements for future clinical practice.

\section{Statement of Ethics}

All institutions obtained institutional review board approval prior to patient recruitment, and all patients signed approved informed consent documents prior to trial enrollment. We confirm that our research complies with the guidelines for human studies and was conducted ethically in accordance with the World Medical Association Declaration of Helsinki.

\section{Conflict of Interest Statement}

Dr. Langer reports personal fees (Advisory Board) from BMS, personal fees (Advisory Board; DSMC) from Lilly, personal fees (DSMC) from Amgen, personal fees (DSMC) from Peregrine, personal fees (DSMC) from Synta, personal fees (Advisory Board) from Roche-Genentech, grants and personal fees (Advisory Board) from Ariad, grants and personal fees (Advisory Board) from Clovis, and grants and personal fees (Advisory Board) from Merck, outside the submitted work. Dr. Rimm reports grants from Genoptix, personal fees from BMS, grants from Gilead, personal fees from Novartis, grants and personal fees from Perkin Elmer, and personal fees from Bethyl Laboratories, outside the submitted work. Dr. Knisely reports personal fees support for meeting atten- 
dance and an honorarium and nonfinancial support from Brainlab $A G$, and nonfinancial support from Elekta $A B$ and from Cyber Medical Corporation, outside the submitted work.

\section{Funding Sources}

This project was supported by grants U10CA21661 (RTOGOps-Stat), U10CA180868 (NRG Oncology Operations), and U10CA180822 (NRG Oncology SDMC), U10CA37422 (CCOP) from the National Cancer Institute (NCI).

\section{Author Contributions}

J.K.: conception and design; W.C., L.S., M.P., C.L., E.M., A.D., J.A., L.K., C.S., S.H., and A.D.: concept and acquisition of data; D.R.: methodology and resources; M.V., V.N., and J.H.: research investigation and data/evidence collection; M.W. and P.Z.: computations-statistical analysis and interpretation of data; M.V. and J.K.: writing - original drafting, review, and editing; and J.K.: study supervision.

\section{References}

1 Ostrom QT, Gittleman H, Farah P, Ondracek A, Chen Y, Wolinsky Y, et al. CBTRUS statistical report: primary brain and central nervous system tumors diagnosed in the United States in 2006-2010. Neuro Oncol. 2013; 15(Suppl 2):ii1-56.

2 Stupp R, Hegi ME, van den Bent MJ, Mason WP, Weller M, Mirimanoff RO, et al. Changing paradigms: an update on the multidisciplinary management of malignant glioma. Oncologist. 2006;11(2):165-80.

3 Mutter N, Stupp R. Temozolomide: a milestone in neuro-oncology and beyond? Expert Rev Anticancer Ther. 2006;6(8):1187-204.

4 Johnson DR, O’Neill BP. Glioblastoma survival in the United States before and during the temozolomide era. J Neurooncol. 2012; 107(2):359-64.

5 Dresemann G. Temozolomide in malignant glioma. Onco Targets Ther. 2010;3:139-46.

6 Wrensch M, Minn Y, Chew T, Bondy M, Berger MS. Epidemiology of primary brain tumors: current concepts and review of the literature. Neuro Oncol. 2002;4(4):278-99.

7 Thakkar JP, Dolecek TA, Horbinski C, Ostrom QT, Lightner DD, Barnholtz-Sloan JS, et al. Epidemiologic and molecular prognostic review of glioblastoma. Cancer Epidemiol Biomarkers Prev. 2014;23(10):1985-96.

8 Parkinson JF, Wheeler HT, McDonald KL. Contribution of DNA repair mechanisms to determining chemotherapy response in highgrade glioma. J Clin Neurosci. 2008;15(1):1-8.

9 Sarkaria JN, Kitange GJ, James CD, Plummer $\mathrm{R}$, Calvert $\mathrm{H}$, Weller M, et al. Mechanisms of chemoresistance to alkylating agents in malignant glioma. Clin Cancer Res. 2008;14(10): 2900-8.

10 Casorelli I, Russo MT, Bignami M. Role of mismatch repair and MGMT in response to anticancer therapies. Anticancer Agents Med Chem. 2008;8(4):368-80.

11 Frosina G. DNA repair and resistance of gliomas to chemotherapy and radiotherapy. Mol Cancer Res. 2009;7(7):989-99.

12 Welsh JW, Ellsworth RK, Kumar R, Fjerstad K, Martinez J, Nagel RB, et al. Rad51 protein expression and survival in patients with glioblastoma multiforme. Int J Radiat Oncol Biol Phys. 2009;74(4):1251-5.
13 Filipowicz W, Bhattacharyya SN, Sonenberg $\mathrm{N}$. Mechanisms of post-transcriptional regulation by microRNAs: are the answers in sight? Nat Rev Genet. 2008;9(2):102-14.

14 Camps C, Buffa FM, Colella S, Moore J, Sotiriou $\mathrm{C}$, Sheldon $\mathrm{H}$, et al. hsa-miR-210 Is induced by hypoxia and is an independent prognostic factor in breast cancer. Clin Cancer Res. 2008;14(5):1340-8.

15 Malzkorn B, Wolter M, Liesenberg F, Grzendowski M, Stühler K, Meyer HE, et al. Identification and functional characterization of microRNAs involved in the malignant progression of gliomas. Brain Pathol. 2010 May; 20(3):539-50.

16 Minami A, Nakanishi A, Ogura Y, Kitagishi Y, Matsuda S. Connection between tumor suppressor BRCA1 and PTEN in damaged DNA repair. Front Oncol. 2014;4:318.

17 Kao GD, Jiang Z, Fernandes AM, Gupta AK, Maity A. Inhibition of phosphatidylinositol3-OH kinase/Akt signaling impairs DNA repair in glioblastoma cells following ionizing radiation. J Biol Chem. 2007;282(29):2120612.

18 Hall JM, Lee MK, Newman B, Morrow JE, Anderson LA, Huey B, et al. Linkage of earlyonset familial breast cancer to chromosome 17q21. Science. 1990;250(4988):1684-9.

19 Miki Y, Swensen J, Shattuck-Eidens D, Futreal PA, Harshman K, Tavtigian S, et al. A strong candidate for the breast and ovarian cancer susceptibility gene BRCA1. Science. 1994;266(5182):66-71.

20 Granzotto A, Bencova Z, Vogin G, Devic C, Joubert A, Balosso J, et al. Brain tumors-current and emerging therapeutic strategies. InTech; 2011. p. 89-104.

21 Boukerroucha M, Josse C, Segers K, El-Guendi $S$, Frères $P$, Jerusalem G, et al. BRCA1 germline mutation and glioblastoma development: report of cases. BMC Cancer. 2015;15: 181.

22 Umphlett M, Shea S, Tome-Garcia J, Zhang Y, Hormigo A, Fowkes M, et al. Widely metastatic glioblastoma with BRCA1 and ARID1A mutations: a case report. BMC Cancer. 2020; 20(1):47.

23 Hanna JA, Wimberly H, Kumar S, Slack F, Agarwal S, Rimm DL. Quantitative analysis of
microRNAs in tissue microarrays by in situ hybridization. Biotechniques. 2012;52(4): 235-45.

24 Bordeaux J, Welsh A, Agarwal S, Killiam E, Baquero M, Hanna J, et al. Antibody validation. Biotechniques. 2010;48(3):197-209.

25 Camp RL, Chung GG, Rimm DL. Automated subcellular localization and quantification of protein expression in tissue microarrays. Nat Med. 2002;8(11):1323-7.

26 Kaplan EL, Meier P. Nonparametric estimation from incomplete observations. J Am Stat Assoc. 1958;53(282):457-81.

27 Mantel N. Evaluation of survival data and two new rank order statistics arising in its consideration. Cancer Chemother Rep. 1966;50(3): 163-70.

28 Cox DR. Regression models and life-tables. J R Stat Soc: Ser B. 1972;34(2):187-202.

29 Lee SA, Dritschilo A, Jung M. Role of ATM in oxidative stress-mediated c-Jun phosphorylation in response to ionizing radiation and CdCl2. J Biol Chem. 2001 13;276(15):1178390.

30 Wrensch M, Jenkins RB, Chang JS, Yeh RF, Xiao Y, Decker PA, et al. Variants in the CDKN2B and RTEL1 regions are associated with high-grade glioma susceptibility. Nat Genet. 2009;41(8):905-8.

31 Sanson M, Hosking FJ, Shete S, Zelenika D, Dobbins SE, Ma Y, et al. Chromosome 7p11.2 (EGFR) variation influences glioma risk. Hum Mol Genet. 2011;20(14):2897-904.

32 Shete S, Hosking FJ, Robertson LB, Dobbins SE, Sanson M, Malmer B, et al. Genome-wide association study identifies five susceptibility loci for glioma. Nat Genet. 2009;41(8):899904.

33 Nageeb AM, Mohamed MM, Ezz El Arab LR, Khalifa MK, Swellam M. Next generation sequencing of BRCA genes in glioblastoma multiform Egyptian patients: a pilot study. Arch Physiol Biochem. 2020;1-9.

34 Tan DS, Rothermundt C, Thomas K, Bancroft E, Eeles R, Shanley S, et al. "BRCAness" syndrome in ovarian cancer: a case-control study describing the clinical features and outcome of patients with epithelial ovarian cancer associated with BRCA1 and BRCA2 mutations. J Clin Oncol. 2008;26(34):5530-6.
BRCA1 Protein Predicts Survival in Glioblastoma Multiforme
Oncology 2021;99:580-588 DOI: $10.1159 / 000516168$ 
35 Cornelis RS, Neuhausen SL, Johansson O, Arason A, Kelsell D, Ponder BA, et al. High allele loss rates at $17 \mathrm{q} 12-\mathrm{q} 21$ in breast and ovarian tumors from BRCAl-linked families. The breast cancer linkage consortium. Genes Chromosomes Cancer. 1995;13(3):203-10.

36 Osorio A, de la Hoya M, Rodríguez-López R, Martínez-Ramírez A, Cazorla A, Granizo JJ, et al. Loss of heterozygosity analysis at the BRCA loci in tumor samples from patients with familial breast cancer. Int J Cancer. 2002; 99(2):305-9.

37 Catteau A, Morris JR. BRCA1 methylation: a significant role in tumour development? Semin Cancer Biol. 2002;12(5):359-71.

38 Geisler JP, Hatterman-Zogg MA, Rathe JA, Buller RE. Frequency of BRCA1 dysfunction in ovarian cancer. J Natl Cancer Inst. 2002; 94(1):61-7.

39 Merajver SD, Pham TM, Caduff RF, Chen M, Poy EL, Cooney KA, et al. Somatic mutations in the BRCA1 gene in sporadic ovarian tumours. Nat Genet. 1995;9(4):439-43.

40 Clark-Knowles KV, Garson K, Jonkers J, Vanderhyden BC. Conditional inactivation of BRCA1 in the mouse ovarian surface epithelium results in an increase in preneoplastic changes. Exp Cell Res. 2007;313(1):133-45.

41 Xing D, Orsulic S. A mouse model for the molecular characterization of brcal-associated ovarian carcinoma. Cancer Res. 2006;66(18): 8949-53.

42 Thrall M, Gallion HH, Kryscio R, Kapali M, Armstrong DK, DeLoia JA. BRCA1 expression in a large series of sporadic ovarian carcinomas: a Gynecologic Oncology Group study. Int J Gynecol Cancer. 2006 Jan-Feb; 16(Suppl 1):166-71.

43 Quinn JE, James CR, Stewart GE, Mulligan JM, White P, Chang GK, et al. BRCA1 mRNA expression levels predict for overall survival in ovarian cancer after chemotherapy. Clin Cancer Res. 2007;13(24):7413-20.

44 Clark-Knowles KV, O’Brien AM, Weberpals JI. BRCA1 as a therapeutic target in sporadic epithelial ovarian cancer. J Oncol. 2010;2010: 891059.

45 Foray N, Marot D, Gabriel A, Randrianarison V, Carr AM, Perricaudet M, et al. A subset of ATM- and ATR-dependent phosphorylation events requires the BRCA1 protein. EMBO J. 2003;22(11):2860-71.

46 Lee JH, Paull TT. Activation and regulation of ATM kinase activity in response to DNA double-strand breaks. Oncogene. 2007;26(56): 7741-8.

47 Venkitaraman AR. Functions of BRCA1 and BRCA2 in the biological response to DNA damage. J Cell Sci. 2001;114(Pt 20):3591-8.

48 Bhattacharyya A, Ear US, Koller BH, Weichselbaum RR, Bishop DK. The breast cancer susceptibility gene BRCA1 is required for subnuclear assembly of Rad51 and survival following treatment with the DNA cross-linking agent cisplatin. J Biol Chem. 2000;275(31): 23899-903.

49 Corde S, Balosso J, Elleaume H, Renier M, Joubert A, Biston MC, et al. Synchrotron photoactivation of cisplatin elicits an extra number of DNA breaks that stimulate RAD51-mediated repair pathways. Cancer Res. 2003; 63(12):3221-7.

50 Pilié PG, Tang C, Mills GB, Yap TA. State-ofthe-art strategies for targeting the DNA damage response in cancer. Nat Rev Clin Oncol. 2019 Feb;16(2):81-104.

51 ESMO OncologyPRO [Internet]. Anti-Cancer Agents and Biological Therapy: Breast Cancer: Current approvals as of May 2019 [cited 2019 May]. Available from: https://on- cologypro.esmo.org/oncology-in-practice/ anti-cancer-agents-and-biological-therapy/ parp-inhibition-and-dna-damage-response$\mathrm{ddr} /$ parp-inhibitors/clinical-activity/breastcancer/current-approvals.

$52 \mathrm{NIH}$, National Cancer Institute [Internet]. With Two FDA Approvals, Prostate Cancer Treatment Enters the PARP Era [cited 2020 Jun]. Available from: https://www.cancer. gov/news-events/cancer-currents-blog/2020/ fda-olaparib-rucaparib-prostate-cancer.

53 AstraZeneca, Media [Internet]. Lynparza approved in the US as a 1st-line maintenance treatment of germline BRCA-mutated metastatic pancreatic cancer [published $2019 \mathrm{Dec}$ ]. Available from: https://www.astrazeneca. com/media-centre/press-releases/2019/lynparza-approved-in-the-us-as-a-1 st-linemaintenance-treatment-of-germline-brcamutated-metastatic-pancreatic-cancer-30122019.html.

54 Tentori L, Ricci-Vitiani L, Muzi A, Ciccarone F, Pelacchi F, Calabrese R, et al. Pharmacological inhibition of poly (ADP-ribose) polymerase-1 modulates resistance of human glioblastoma stem cells to temozolomide. BMC Cancer. 2014;14:151.

55 Karpel-Massler G, Pareja F, Aimé P, Shu C, Chau L, Westhoff MA, et al. PARP inhibition restores extrinsic apoptotic sensitivity in glioblastoma. PLoS One. 2014;9(12):e114583.

56 Barazzuol L, Jena R, Burnet NG, Meira LB, Jeynes JC, Kirkby KJ, et al. Evaluation of poly (ADP-ribose) polymerase inhibitor ABT-888 combined with radiotherapy and temozolomide in glioblastoma. Radiat Oncol. 2013;8:65.

57 NIH U.S. National Library of Medicine ClinicalTrials.gov [Internet]. 19 Studies found for: PARP AND glioma. Available from: https:// goo.gl/IgswbE (checked 2020 Dec). 